Article

www.mdpi.com/journal/challenges

\title{
How China's Options Will Determine Global Warming
}

Clifford Singer $^{1, *}$, Timothy Milligan ${ }^{2}$ and T.S. Gopi Rethinaraj ${ }^{3}$

${ }^{1}$ University of Illinois at Urbana-Champaign, Department of Nuclear, Plasma, and Radiological Engineering, MC-234, Urbana, IL 61801, USA

${ }^{2}$ Knox Interactive, 11523 State Highway 37, Benton, IL 62812, USA;

E-Mail: milligantim1@gmail.com

${ }^{3}$ National University of Singapore, Lee Kuan Yew School of Public Policy, 469C Bukit Timah Road, Singapore 259772, Singapore; E-Mail: spptsgr@nus.edu.sg

* Author to whom correspondence should be addressed; E-Mail: csinger@illinois.edu; Tel.: +1-217-333-1814.

Received: 25 October 2013; in revised form: 12 December 2013 / Accepted: 13 December 2013 / Published: 30 December 2013

\begin{abstract}
Carbon dioxide emissions, global average temperature, atmospheric $\mathrm{CO}_{2}$ concentrations, and surface ocean mixed layer acidity are extrapolated using analyses calibrated against extensive time series data for nine global regions. Extrapolation of historical trends without policy-driven limitations has China responsible for about half of global $\mathrm{CO}_{2}$ emissions by the middle of the twenty-first century. Results are presented for three possible actions taken by China to limit global average temperature increase to levels it considers to be to its advantage: (1) Help develop low-carbon energy technology broadly competitive with unbridled carbon emissions from burning fossil fuels; (2) Entice other countries to join in limiting use of what would otherwise be economically competitive fossil fuels; (3) Apply geo-engineering techniques such as stratospheric sulfur injection to limit global average temperature increase, without a major global reduction in carbon emissions. Taking into account China's expected influence and approach to limiting the impact of anthropogenic climate change allows for a narrower range of possible outcomes than for a set of scenarios that are not constrained by analysis of likely policy-driven limitations. While China could hold back on implementing geoengineering given a remarkable amount of international cooperation on limiting fossil carbon burning, an outcome where geoengineering is used to delay the perceived need to limit the atmospheric $\mathrm{CO}_{2}$ concentration may be difficult to avoid.
\end{abstract}


Keywords: China; carbon emissions; geo-engineering

\section{Introduction}

How much will global average temperature increase in the twenty-first century? This is an important and as yet unanswered question for those who have to plan for the effects of climate change but cannot control it. Answering this question requires insight into how climate change will alter national policies. For a world with many comparable greenhouse gas emitters, understanding the complexity of domestic and international interactions affecting climate change would be extraordinarily daunting. However, the econometric analysis in the present paper suggests that by the mid-twenty-first century there will be one dominant emitter of $\mathrm{CO}_{2}$ as the dominant greenhouse gas: China. As described in the following section, Figure 1 shows two possible outcomes for China's fraction of global carbon emissions through 2050 . Either such outcome suggests that China's preference for the eventual level of global average temperature increase will thus strongly influence the actual outcome. Here we examine the consequences of China's preference being for about $3{ }^{\circ} \mathrm{C}$ increase over the preindustrial level, and ask whether China can ensure such an outcome. This exercise illustrates the potential ramifications of such a preference and points out the importance of detailed studies aimed at illuminating what China's preference is actually likely to be.

Figure 1. Fraction of global carbon emissions rate from China, Mongolia, and North Korea, extrapolated from historical data without (dashed curve) and with an assumption that this region's long-term limit per capita GDP is equal to the limit for the USA region (solid curve).

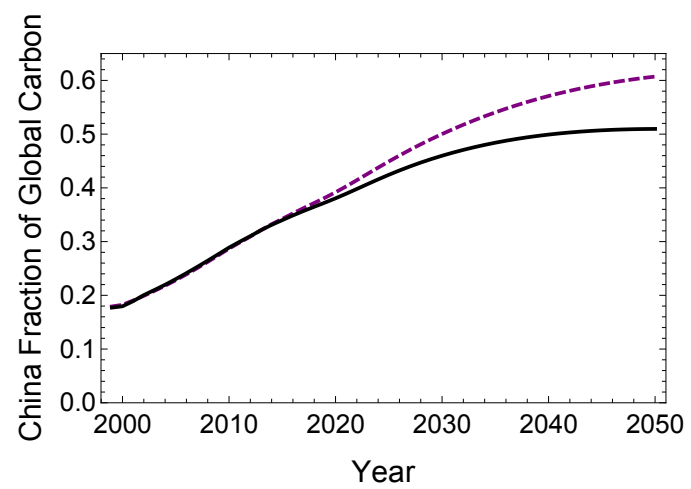

We examine three possible ways that China can guide the world to that country's desired outcome. (1) Help develop low-carbon energy technology broadly competitive with unbridled carbon emissions from burning fossil fuels; (2) Entice other countries to join in limiting use of what would otherwise be economically competitive fossil fuels; (3) Apply geo-engineering techniques to limit global average temperature increase, without a major global reduction in combustion of fossil carbon. It is not now known how to succeed at the first of these three options. We include it here because it is also not known to be infeasible. However, the focus here is on the tension between the other two options. We assume in particular that China will be willing and able to unilaterally limit temperature increase by injecting sulfur into the stratosphere, at least if China cannot achieve a global reduction in carbon emissions sufficient to 
meet its temperature limit goal. Amongst other possible approaches to geoengineering [1], we focus here on stratospheric sulfur injection because it could be done unilaterally from sovereign territory. While recapture and sequestration of $\mathrm{CO}_{2}$ from the atmosphere could also be done within China and might be preferable as a sole solution from a global environmental perspective, stratospheric sulfur injection appears to involve considerably less direct cost.

To examine the consequences of the above three options, we couple extrapolations of historical energy use trends with global heat and carbon balance analyses. The purpose is just to provide a conceptual illustration of feedback from climate change on policy, so we use a simple unified global heat balance and a simple four-chamber global carbon balance model. The key results are global average temperature response to carbon emissions, atmospheric $\mathrm{CO}_{2}$ concentrations, and the hydrogen ion activity of the top $335 \mathrm{~m}$ of the ocean.

For extrapolation of historical energy use patterns, we divide the world into nine country groups. Each group's economy has an energy sector and a sector containing the rest of the group's economic output. Capital and labor in each sector are adjusted to maximize the total per capita utility of consumption, integrated over time after discounting at a fixed social discount rate, as described in Appendix B. Each energy sector production function depends on the sector's capital, labor, and carbon intensity of energy use, and a logistically evolving productivity factor. The production function for the rest of the economy depends on its energy use rate, all capital stock not used for energy production, labor not applied to energy production, and the same logistically evolving productivity factor. The group including China contains Taiwan and also includes Mongolia and North Korea. The carbon emissions of that group are completely dominated by the People's Republic of China. For the other eight groups, calibration was done using time series data starting after the readjustment from World War II. Including the former Soviet block and Western Europe in the same group avoided the complication of detailed tracking of readjustments of the comparatively small economic production of the Soviet block after the collapse of the Soviet Union. A list of the countries in each group is given in Appendix A. The equations and solution methods used for the welfare maximization problem are described in Appendix B.

The total energy consumption in each region specified by the model outlined above was broken down into seven components. These are conventional biofuels, coal, oil, natural gas, and three sets of non-fossil electrical energy sources. The latter included nuclear, water-driven, and other renewable electrical energy sources. Water-driven electricity includes hydroelectric power and small contributions from geothermal electric and tidal electric power production. "Other renewable electrical energy sources" include wind, solar thermal electric, and grid-connected photovoltaic systems. Conventional biofuels include biodiesel and fuel ethanol. The method for extrapolating the use of each of the seven classes of energy sources is described in Appendix D. The methods for constructing the database that was used are outlined in Appendix G. The composition of energy sources was used to compute the carbon intensity of energy production used in the overall economic model described above. This process was iterated to make the carbon intensity used in the energy production function in the overall economic model consistent with that computed from the breakdown into different energy sources.

The evolution of the fraction of the rate of global carbon burning due to the China group is shown in Figure 1. The upper curve in Figure 1 is a simple extrapolation of historical trends, using the methods described in Appendix B. The lower curve assumes that the long-term limit in GDP increment over 
its 1820 value divided by long-term population increment over its 1820 value is no larger for any country group than for the USA group. This assumption affects the long-term GDP limit of the China, Brazil, and Indonesia groups. The difference between the upper and lower curves in Figure 1 give some indication of the substantial uncertainties in long-term extrapolation of GDP, and associated energy use rates, for countries far from approaching their long-term limits. Throughout the rest of this article, the assumptions on GDP used to produce the lower curve in Figure 1 are used.

The portion of the China group's carbon emissions accounted for by the People's Republic of China (PRC) was 92\% and growing in 2012. So even if its policies are not coordinated with others in its region, by mid-century the PRC the lower curve in Figure 1 suggests that China's policies will play a dominant role in determining the future of climate change. The following section gives an example of how China might limit the increase of global average temperature over is preindustrial average to $3{ }^{\circ} \mathrm{C}$ without any substantial cooperation from other countries on limiting carbon emissions until the twenty-third century. The section after that examines an alternative where China promptly begins to engage the rest of the world in a cooperative effort to limit carbon burning.

\section{Geo-Engineering}

A way to explore how China might act to limit the increase of global average temperature is to prescribe an effect of stratospheric sulfur injection sufficient to do so, as shown in Figure 2. For this example, based on the analysis described in Appendix E, the global average temperature increase over its preindustrial value to $3{ }^{\circ} \mathrm{C}$ until after 2200 is limited by enough sulfur injection to sufficiently reduce net effective insolation proportional to $\left.\left.S=1 /\left[1+e^{-\left(t_{y}-2065\right) / 10}\right)\right]+0.925 /\left[1+e^{-\left(t_{y}-2150\right) / 25}\right)\right]$, where $t_{y}$ is in Julian years. The first of these two terms "buys time" to keep global average temperature increase over its preindustrial average to under $\tau=2.5{ }^{\circ} \mathrm{C}$ in the through the twenty-first century. Eventually, however, implementation of carbon sequestration is necessary to keep the atmospheric $\mathrm{CO}_{2}$ from exceeding $2,500 \mathrm{ppmv}$ by the year 2200. Sequestering a fraction $\left.0.78 /\left[1+e^{-\left(t_{y}-2150\right) / 25}\right)\right]$ of annual fossil carbon burning suffices with both terms in the formula for $S$ included. Otherwise, the atmospheric $\mathrm{CO}_{2}$ concentration reaches 2,885 ppmv by 2200 , is then increasing at the rate of $189 \mathrm{ppmv}$ per decade, and eventually exceeds the current U.S. occupational limit of 5,000 ppmv.

Figure 2. Temperature changes with stratospheric sulfur injection, followed later by carbon sequestration.

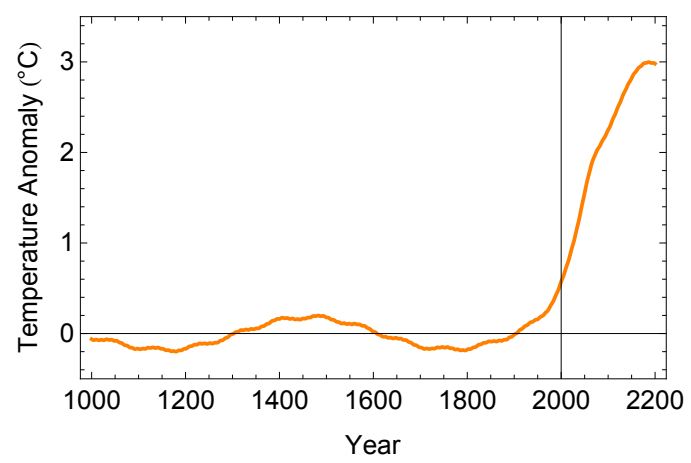


Recent experimental studies on human subjects have detected "large and statistically significant reductions" at 2,500 ppmv $\mathrm{CO}_{2}$ "in seven scales of decision-making performance" [2]. Thus, having the entire global population exposed to 5,000 ppmv might prove unacceptable. Also, even with the schedule for carbon sequestration just mentioned, the surface ocean mixed layer acidification from Julian year 1820 to 2200 is a decline of $0.76 \mathrm{pH}$ units. (The surface ocean mixed layer is here approximated as the top $335 \mathrm{~m}$, as described in Appendix E.) The increase in the rate of stratospheric sulfur injection indicated by the second term in the above expression for $S$ is also needed to avoid $\tau>3{ }^{\circ} \mathrm{C}$ through the twenty-second and twenty-third centuries.

The results just reported suggest that relying initially primarily on stratospheric sulfur injection to limit temperature could potentially result in serious environmental effects. There could also be a very rapid increase in global average temperature if stratospheric sulfur injection is ever discontinued. For example, suppose that additions of sulfur to the stratosphere designed to produce the effects described in the previous paragraph suddenly stop in Julian year 2150. Suppose also that the effect of previous injections on net insolation declines exponentially at a rate of $1 /(1.5$ year) [3] due to loss of aerosols from the atmosphere. Thereafter, instead of the result show in Figure 2 the temperature anomaly reaches $\tau=3.8{ }^{\circ} \mathrm{C}$ after 10 years and $4.7^{\circ} \mathrm{C}$ after 20 years. Relying primarily on continuous stratospheric sulfur injection could thus put the world at risk that an economic or political instability serious enough to interrupt the injection for a decade or more would be compounded by a far more rapid temperature increase than the already problematic rise that had already occurred. Despite potential risks illustrated in part by the results presented here, in the absence of effective global cooperation on limiting atmospheric $\mathrm{CO}_{2}$ a geo-engineering approach using stratospheric sulfur injection could be the most economic first resort method available to China for managing climate change in the twenty-first century.

\section{Nuclear Dominated De-Carbonization}

To eventually sequester at source $78 \%$ of global carbon burning, as assumed for the result in Figure 2, may require sequestration of nearly all $\mathrm{CO}_{2}$ associated with production of electricity from fossil fuels. A substantial fraction of combustion of fossil fuels for heat and transportation could also need to be switched to energy supplies that either do not produce $\mathrm{CO}_{2}$ or sequester it. One low-carbon alternative to avoid the need to sequester $\mathrm{CO}_{2}$ associated with production of electricity from fossil fuels is the use of nuclear energy. To examine this alternative, we assume that China leads a dramatic switch from fossil to nuclear energy sources. The global carbon emissions trajectory for this case is shown in Figure 3. Details of how this result is produced are described in Appendix D.

Figure 4 compares the evolution of uranium prices for the nuclear-dominated option to the lower curves corresponding to the geoengineered approach described above. (What is shown in Figure 4 corresponds to uranium prices averaged over commodity price variations in order to produce a monotonic increase [4], and adjusted for inflation to year 2012 U.S. purchasing power [5].) The lower curve in Figure 4 shows evolution of the price of uranium consistent with the geoengineering approach described above. The upper curve shows the results for a case that produces the global carbon emissions profile shown in Figure 3 and limits global average temperature increase through 2300 to $2.96{ }^{\circ} \mathrm{C}$. The evolution of global carbon emissions shown in Figure 3 is consistent with China soon making a 
decision to develop mass manufacturing capability for nuclear reactors, and that capability spreading rapidly to the rest of the world. A remarkable pace of such activity would be required for the result in Figure 3 to be realized. This suggests that geoengineering might more likely be used at least in part for China to "buy time" to allow a more measured pace for global energy decarbonization.

Figure 3. Global carbon emissions (in billions of metric tons per year) with a strong shift to nuclear energy use.

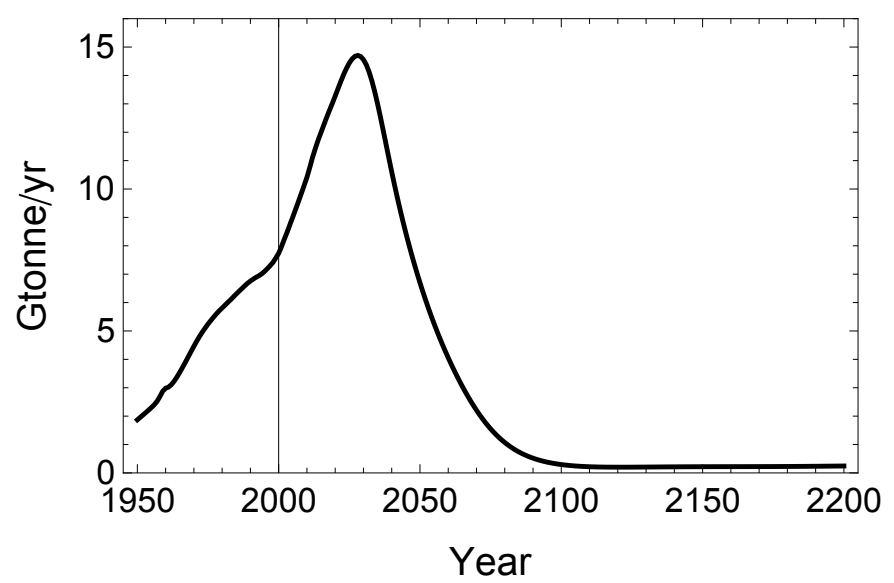

Figure 4. Uranium price with nuclear-led decarbonization (dashed curve), versus a geoengineeered outcome with stratospheric sulfur injection along with subsequent extensive carbon sequestration (solid curve).

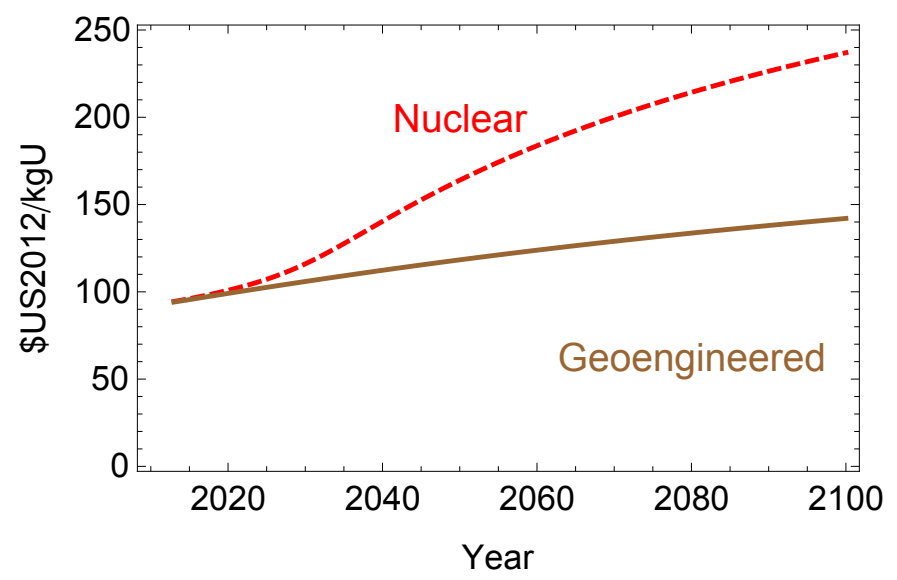

For Figure 4, uranium price as a function of cumulative global use is taken from Singer and von Brevern [4], as described in Appendix F. For simplicity, it is assumed that the amount of uranium used per unit of energy produced is constant in the future. This assumption and the results shown in Figure 4 are consistent with the hypothesis that nuclear energy economics will long not favor reprocessing or very high fuel burnup, so substantial reductions in the amount of uranium used per unit electrical energy produced through such methods are not accounted for here. The uranium price increases shown in Figure 4 are low enough that the impact on nuclear energy economics is small compared to 
uncertainties in other nuclear energy costs. If uranium can be recovered from seawater at a cost [6] less than the uncertainties in other nuclear energy costs, then this approach is potentially sustainable for many centuries.

The upper curve in Figure 4 should be viewed as an extreme result for uranium prices. As detailed in Appendix D, the sum of wind and solar energy is limited in each region to at most $7 \%$ of total thermal energy equivalent in any country group (assuming that each Joule of electrical energy from non-fossil energy sources displaces 1/0.38 Joules of thermal energy use). Water-driven electrical energy production is limited in absolute amounts by geographic restrictions to the largest fractions of maximum potential currently found in any region. Biofuels are assumed to be limited by competition for food production to a small fraction of total energy use. In practice, some of these restrictions might be relaxed, and partial use of geoengineering or carbon sequestration at source might be applied, thus reducing cumulative uranium use.

A third alternative discussed above is that China succeeds in getting extensive global deployment of alternative low-carbon energy technology that is competitive with nuclear energy and fossil fuels. For a case identical to that producing the upper curve in Figure 4, except that a carbon-free energy source based on an alternative to nuclear energy, overall energy use is lower than for the high-carbon case. This is because energy use rates are lower with more expensive low-carbon sources, as described in Appendix C.

With the fraction of total energy from nuclear power the same as for the high-carbon case, the uranium price in 2100 is 10 \$US2012 less than for the lower curve in Figure 4. Thus, the lower curve in Figure 4 approximates the minimum uranium price trajectory for the different cases explored here. For anything between the lower and upper curves in Figure 4, the price of mined uranium contributes only a few percent of the total cost of nuclear electric energy generation, and well within the uncertainty in that total cost. This result is only included only to point out that depletion of global uranium resources is not included as a significant factor affecting overall nuclear energy use. To actually achieve decarbonization through such a pronounced shift to nuclear energy would require a very substantial capital investment, which could be expected to be difficult to coordinate on the required global scale in the absence of strong economic incentives connected with regional effects of pollution from coal burning and large increases in the price of fluid fossil fuels.

\section{Would Global De-Carbonization Require Government Policies?}

Will the effect on prices of depletion of fluid fossil fuel resources be sufficient to drive radical energy de-carbonization in this century? The results in Figures 5 and 6 suggest not.

Figure 5 plots the increase in average wellhead natural gas costs for the two cases with results shown in Figure 4. Wellhead cost as a function of global use is taken from fits to information gathered by Rogner H.-H. [7], as described in Appendix F. A simplifying assumption here is that, as wellhead costs become comparable to shipping costs, a global market evolves for natural gas as well as for oil, so a global analysis becomes sufficient. 
Figure 5. Natural gas wellhead cost with nuclear-led decarbonization (dashed curve), versus a geoengineeered outcome with stratospheric sulfur injection along with subsequent extensive carbon sequestration (solid curve).

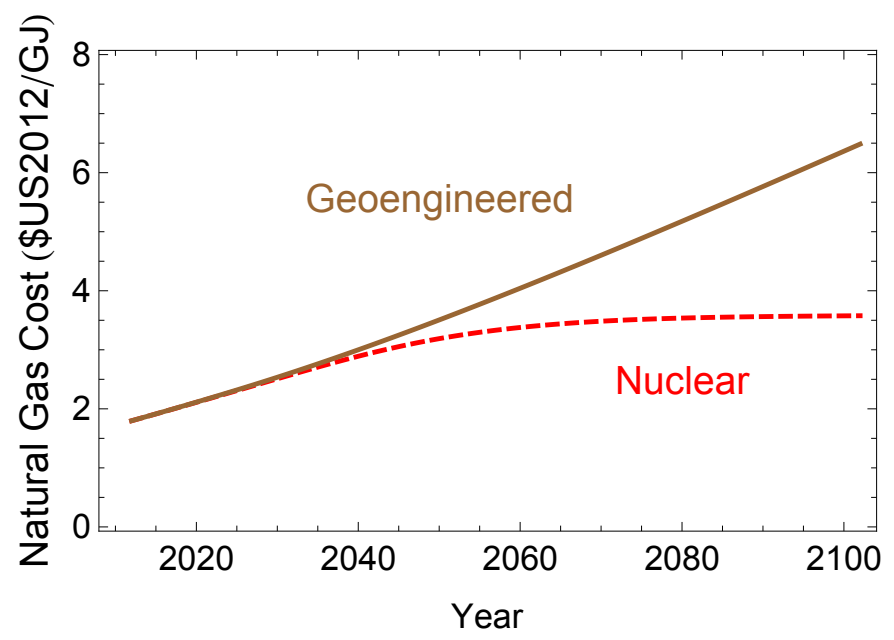

Figure 6. Oil wellhead cost with nuclear-led decarbonization (solid curve), versus a geoengineeered outcome with stratospheric sulfur injection along with subsequent extensive carbon sequestration (solid curve).

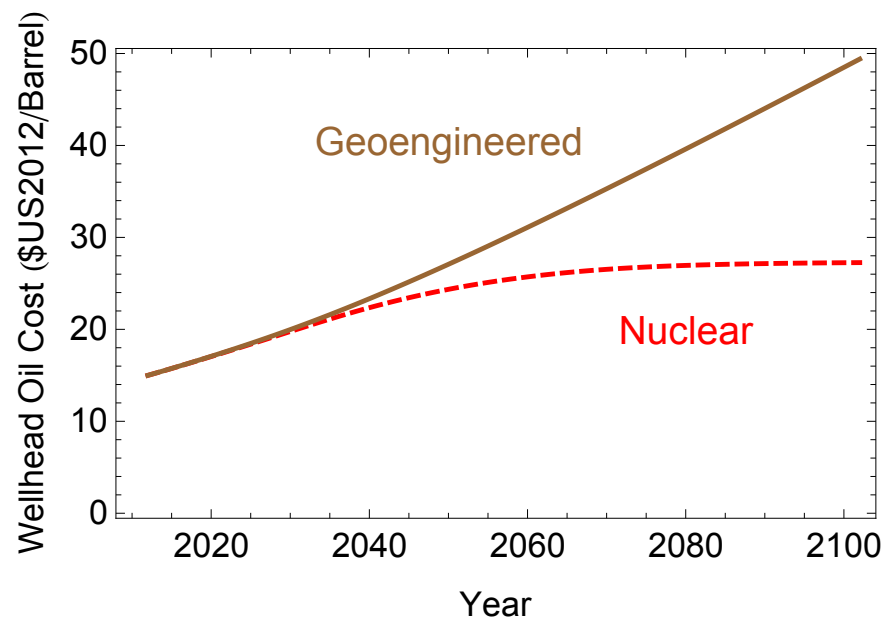

While natural gas prices in some markets can be substantially higher than wellhead costs plus c. 3 \$/GJ to get natural gas to power plants, this is not a situation that is sustainable if prices remain high enough to make natural gas uncompetitive with other energy sources. Throughout the twenty-first century, the wellhead costs shown in Figure 5 may well remain low enough to keep natural gas competitive with other electrical energy supplies in the absence of substantial carbon taxes or other governmental intervention.

Trends toward a lower fraction of coal use due to regional pollution concerns and the greater convenience of fluid fuels are reflected in historical data and thus are accounted for in our analysis. However, combined with our results, Rogner's analysis suggests that depletion of coal resources will not have sufficient additional impact on production costs to force a major reduction in coal use in this century 
without government action to discourage coal burning (c.f. Appendix F). The conclusion drawn in this section is that China will need to get governments of other major carbon-burning countries to cooperate on de-carbonization if the geo-engineering dominated approach is to be avoided, because depletion of fossil fuel resource alone will not force adequate energy decarbonization.

China's likely goal for temperature depends on the effects of climate change and the cost of limiting that change. The order of magnitude of costs involved in country-wide changes in China's energy use is evident from a year 2013 announcement by the Chinese government of a plan to spend \$275 billion over five years to improve air quality [8]. Concerning the more distant future Chinese economy, there remains a wide spread of results in analysis of the impact of both climate change and the cost of various possible mixes of decarbonization and geoengineering. Economic effects have been examined without and with allowing for readjustment to a new economic equilibrium. For example, without allowing for a new economic equilibrium, Mendelsohn et al. [9] developed country-specific climate response cost functions with a positive GDP response for China up to $3{ }^{\circ} \mathrm{C}$ global temperature increase.

Bosello and Roson [10] summarize results from various studies, including one by Nordhaus and Boyer [11]. The $3{ }^{\circ} \mathrm{C}$ limit chosen here for the purposes of illustration is compatible with a $2{ }^{\circ} \mathrm{C}$ optimum with no cost to China for reaching that limit and a balance of $70 q$ \$US2010 per tonne of carbon burned by China. Here $q$ is the percent reduction of China's GDP per ${ }^{\circ} \mathrm{C}$ increase above $2{ }^{\circ} \mathrm{C}$ in global average temperature. An original set of results by Nordhaus and Boyer that were re-analyzed by Bosello and Roson suggest $q \sim 1$. However, that reanalysis gave the opposite sign for $q$ for China when $\tau=2{ }^{\circ} \mathrm{C}$, which illustrates the need for further studies of this question. Thus, a complete analysis of the expected dynamic response of China's economy to climate change appears to be needed to better define China's likely actual goal for limiting global warming.

\section{China's Interactions with Other Countries}

Threatening war or economic sanctions to force other major carbon burners to drastically decarbonize risks unproductive confrontation that could be quite damaging to China's security or economy. Preparing to exercise a geo-engineering option may instead be China's least risky approach to encouraging other countries to cooperate with it on energy de-carbonization. While there are other possibilities, we focus on stratospheric sulfur injection as an approach that appears to be manageable from a cost perspective, even if pursued by China unilaterally.

There is no approach to China's goal of limiting temperature increase that is without risks. Stratospheric sulfur injection will have differential environmental and economic effects on different countries, and some may strenuously object. Also, based on historical events, one cannot rule out a major catastrophe sometime within the time frame examined here, such as a highly lethal global pandemic or an accidental nuclear war. Should there be a catastrophe of sufficient proportions to interrupt, for more than a year, sulfur injections after the atmospheric $\mathrm{CO}_{2}$ concentration has built up to well over 2,000 parts per million by volume (ppmv), then that catastrophe would be augmented by a rapid rise in global average temperature. After a decade or more of such interruption, the temperature of the surface ocean mixing layer would be expected to increase as described quantitatively above. That could lead to drastic and irreversible consequences. 
Preparations by China to begin large scale stratospheric sulfur injection could thus provide an impetus for other major carbon emitters to agree to cooperate on sufficient energy sector de-carbonization to meet China's goal for limiting temperature increase. Absent such impetus, experience to date suggests that overcoming the various domestic political impediments to such agreement by industrialized democracies might be more problematic. It is possible that domestic impediments within China could also prevent it from agreeing to and implementing the necessary energy sector changes without resorting to large-scale geo-engineering. However, a continuation of China's current political organizational structure may make it easier for that country to lead the way to an effective international agreement on global energy de-carbonization than for any other country or group of countries to do so.

\section{Implications for Future Analysis}

Previous Intergovernmental Panel on Climate Change (IPCC) integrated assessments have concentrated on evaluating the consequences of various scenarios for future greenhouse gas emissions. An IPCC report issued in the year 2000 described the scenarios used at the time as "equally valid with no assigned probabilities of occurrence" [12]. Cumulative carbon emissions from 1990-2100 in the IPCC scenarios range from less than 0.8 to more than 2.5 trillion metric tons, with a corresponding wide spread in global average temperature increase by the year 2100. A set of four scenarios used more recently for IPCC work has atmospheric $\mathrm{CO}_{2}$ concentrations in 2100 ranging from about [13]. While analysis of such scenarios provides a very useful description of possible outcomes, there is a broad group of stakeholders who have a need for a probabilistic assessment of the actual outcome. Making a sensible such assessment requires some understanding of the likely mechanism for climate change to feedback on policies on emissions of greenhouse gases, particularly of $\mathrm{CO}_{2}$.

The present paper suggests a plausible approach to analyzing the likely feedback of climate change on carbon emissions. First, use extensive time-series data to carefully calibrate probability distributions for a priori uncertain parameters in energy economics models. (While only maximum likelihood results are given here, methodology for calibrating such probability distributions is described by Singer et al. [14].) Then use the resulting greenhouse gas emissions as forcing functions in a detailed analysis of climate change and its impact on dynamic adjustment towards general economic equilibrium, concentrating first on a detailed assessment for China. On this basis analyze China's alternatives for unilateral geo-engineering and cooperative global energy de-carbonization. Also examine the dynamic adjustment towards general economic equilibrium of other significant greenhouse gas emitters with and without China carrying through with geo-engineering, cooperative de-carbonization, or various combinations thereof. This is a substantial but potentially manageable challenge. Given the importance of the issue, it seems well worth pursuing.

One speculation is that the outcome of the research exercise just proposed would lead to a greater than fifty percent probability of global average temperature increase over pre-industrial values lying within $0.5^{\circ} \mathrm{C}$ of $3{ }^{\circ} \mathrm{C}$, or whatever range of uncertainty there is about the amount of global warming that China will find acceptable. This result could follow from various combinations of geo-engineered and energy de-carbonization response, with very different ecological and economic consequences, all within the same fairly narrow range of temperature increase. This is despite the present large uncertainty in the 
temperature change response to greenhouse gas emissions, because the proposed approach allows for Chinese-led adaptation to higher or lower climate sensitivity by adjustment of policy-driven response. Whether this speculation will stand up to detailed analysis would be very interesting to see. What is needed to respond to this speculation is a probalistic analysis of actual outcomes, with probability distributions for policy-driven response to climate change included in the analysis.

\section{Appendix}

\section{A. Country Groups}

Country groups are identified by the countries with the largest population in the group as of 2010 . The following eight groups are chosen to have roughly balanced total energy production and consumption in each group, and to be of comparable long-term limit population. Exceptions are that the limit population of the USA group is noticeably smaller than average, and the limit population of the India group is noticeably larger than average. These eight groups are (1) China: People's Republic of China, Democratic People's Republic of Korea, and Mongolia; (2) India: Afghanistan, Bhutan, India, Iran, Maldives, Nepal, Pakistan, and Sri Lanka; (3) Nigeria: Africa south of the Sahel countries that are included with Ethiopia below; (4) Brazil: Western Hemisphere except USA and Canada; (5) Ethiopia-Egypt: Arabian Peninsula, Chad, Djibouti, Egypt, Eritrea, Mali, Mauritania, Niger, Somalia, South Sudan, Sudan, North Africa, Iraq, Israel and the Occupied Territories, Jordan, Lebanon, Syria, Turkey, and Western Sahara; (6) Indonesia: All countries not in other groups, including Pacific islands and the countries in the Association of Southeast Asian Nations; (7) EU: Europe including French overseas island Departments, and the former Soviet Union; and (8) USA: Canada, Guam, Puerto Rico, and U.S. Virgin Islands. In addition, Japan is treated alone as a separate "group" because the 2011 tsunami greatly perturbed its energy mix.

\section{B. Population and GDP}

The parameters discussed in this paragraph are in convenient dimensionless units. The relationship between these parameters and their dimensional counterparts is described below. The utility of per capita consumption $C$ for each country group is taken to be $U=\left((C / L)^{1-\theta}-1\right) /(1-\theta)$, with population approximated as proportional to labor, $L$, and with $\theta$ a universal constant. Population is approximated as a logistic function of time, calibrated against historical data. Total discounted total future welfare starting at a time $t$ is proportional to $\int_{t}^{\infty} L U e^{-\rho t} \mathrm{~d} t$ with social discount rate $\rho$ a universal constant. Consumption is $C=Y / \alpha-r K-\dot{K}$. Here the depreciation rate $r$ is a universal constant, $K$ is capital stock, and $\dot{K}$ is the time rate of change of capital stock. GDP is $Y / \alpha$ with

$$
Y=a\left[((1-\beta k) K)^{\alpha}((1-\beta \ell) L)^{\omega)}\right]^{1-\beta} w^{\beta}
$$

where the rate of energy use is $w=(1+h p) a(k K)^{\alpha}(\ell L)^{\omega}$. Overall economic productivity is a logistic function $a=1 /\left[1+e^{-\nu\left(t-t_{1}\right)}\right]$, with constants $\nu$ and $t_{1}$ calibrated against time-series data for each country group. $\beta k$ and $\beta \ell$ are respectively the fractions of total capital and labor in the energy sector. Welfare is maximized with sustainability as a terminal boundary condition when $K, k$, and $\ell$ solve a set 
of coupled Euler-Lagrange differential equations with regularity as $t \rightarrow \infty$, i.e., as $z=1-a \rightarrow 0$. The universal constant $\omega=1-\alpha$ is the fraction of GDP paid to labor. Carbon intensity $p$ is the carbon/energy use ratio divided by that for coal. The universal constant $1 /(1+h)$ is the ratio of the energy produced with a given productivity and amounts of capital and labor using carbon-free sources to that using high-carbon sources.

In the above equations, time is universally expressed in units of the "capitalization time" $\bar{t}=1 /(\bar{r}+\bar{\rho})$, where $\bar{r}$ is the depreciation rate per year and $\bar{\rho}$ is the social discount rate per year. For each country group, monetary units $K$ are expressed in units of that group's long-term equilibrium limit value of capital stock. All dimensional monetary units are in purchasing power parity (PPP). The energy use rate $w$ is expressed in units of its long-term limit value for each group. The values of the universal parameters used here are taken from Singer et al. [14]. Except for $h=1.5$, these values were calibrated against empirical data. These values are $\alpha=0.325, \theta=1.345, \bar{r}=0.107 /$ year, and $\bar{\rho}=0.218 /$ year, resulting in a "capitalization time" $\bar{t}=7.76$ years. Using the approximation discussed below, the results shown in this paper are independent of the value of the parameter $\beta$. The value used for $h$ is chosen here as an example roughly compatible with a ratio of $h+1=2.5$ in the cost of electricity from non-fossil energy sources and from inexpensive fossil fuels.

The results shown in this paper rely on expansion of the solution of the welfare maximization problem in three parameters. Expanding only to lowest order in the energy fraction of capital, $\beta$, allows the evolution of total capital and GDP to be calibrated against time-series data for GDP independently of data on energy and carbon use. The parameter $\beta$ is a measure of the portion of capital and labor used for procuring energy consumed. That energy can either be produced domestically, imported, or a combination both. Generally that portion is only a few percent, so $\beta$ is a good expansion parameter.

Expansion is through first order in the capitalization lag parameter $\delta=\nu \theta / \omega$. This parameter is a measure of the maximum value of the difference between capital stock and what it would relax to if productivity and labor were frozen, divided by the total capital stock. For some cases, particularly China, we have $\delta \approx 1$, and the results thus provide only a semi-empirical formula for the period of historical time-series data used to calibrate the a priori uncertain parameters in the model for that group. The term "semi-empirical" here is meant to imply that the capitalization lag phenomenon is accounted for, but not in a manner exactly consistent with the similar but more accurate solutions that we have obtained in exploratory work on the China and USA groups using exact numerical solutions with adjustable parameters calibrated against the same data. That numerical integration requires a shooting method starting from a triple power series expansion in $z$ around the regular singular point $z=0$. The nonlinear differential equations to be solved have a movable singular point at larger values of $z$, i.e., earlier times, and great care in choosing the one adjustable boundary condition parameter has to be exercised to get a solution that does not diverge and best matches the historical GDP time-series data. Here we thus use an approach that is much more readily calculated and similar to the exact solution for country groups even where $\delta$ is not small. The resulting formulas share with the exact solutions the property that there is a rapid initial rate of growth of GDP after a perturbation (such as economic reform or war) that initially leaves the economy substantially under-capitalized.

Because of the existence of the movable singularity just described, direct integral maximization approaches using other available software such as the General Algebraic Modeling System (GAMS) can 
have the property of not converging as the number of computational nodes used is increased [15]. Care should thus be exercised when interpreting results in the literature where similar integral maximization problems are solved by approximating the integral at widely spaced time points, unless it has been demonstrated that the solution convergences as the number of time points used is increased.

The formula for per capita GDP in $\mathrm{k} \$ 1990 \mathrm{PPP} / \mathrm{year}, B_{3}\left[a /(1+\delta z)^{\alpha}\right]^{1 / \omega}$, results from the expansion procedure just described. Population in each region is fit to logistic functions of the form $\left.A_{3} /\left[1+e^{-\left(t_{y}-A_{1}\right) / A_{2}}\right)\right]$. We implicitly divide each region's economy into "preindustrial," "industrial," and "post-industrial" components. The preindustrial component always includes the same annual GDP and the population as in the year 1820. The energy database includes coal, oil, natural gas, fuel ethanol, biodiesel, and grid-connected electrical energy. The preindustrial component always includes the same annual coal use as in 1820, and all other energy sources not included in the database. The industrial component includes that part of other GDP that requires some minimum amount of energy use per unit GDP.

Since energy use cannot grow arbitrarily large, neither can the industrial component of GDP. The post-industrial component of GDP contains components such as production of the part of yet-undiscovered intellectual property that requires no additional energy use, which in principle could grow arbitrarily large. This potentially important "post-industrial" part of GDP is assumed to be a negligible part of the GDP in the database. The approach used here is conceptually consistent with the commonly used finite rate for growth of total GDP as a terminal boundary condition, but it allows us to impose a zero rate of growth of the industrial portion of GDP in the long-term limit as a boundary condition. Thus, the formulas given above and below are fit to data on the increments of population, GDP, and energy use, over the year 1820 level; and sustainability in the infinite time limit is used as a terminal boundary condition. The year 1820 approximately marks the beginning of a rapid growth phase of the industrial revolution, before which population and GDP can be adequately approximated for our purposes as constant. Since the initial population and GDP productivity growth in our logistic formulas is exponential, setting aside the 1820 values allows for a better fit to such formulas. Since available data is sparse on wood and other energy sources not in our database, our approach also allows global coverage without the need to make computational use of very incomplete data on other comparatively minor energy sources assumed to continue to be used for sustenance by populations equal to 1820 levels. The 1820 energy use levels subtracted from later years' data for the India, EU, and USA groups are respectively $0.017,0.827$, and 0.009 EJ. Because data on early coal use are incomplete, 1820 base level energy use rates are zero for the other groups. (The small 1820 global carbon burning of 0.021 Gtonne is assumed to reflected in the global temperature equilibrium and is thus not included in calculation of perturbation of that equilibrium by subsequent increases in carbon emissions.) Some of the parameters used are listed in Tables 1-3. In particular, the 1,820 populations $A_{0}$ and GDP levels $B_{0}$ that are subtracted from subsequent years' data are listed in the Table 3.

The population estimates used for least squares calibration of logistic function fits for population start in 1950, with the exception of the China group. Because the "Great Leap" in China dented its population by about thirty million, the fit for the China group's population data starts instead in 1962. Because long-term UN population estimates for China and Japan do not increase monotonically, the time-series data used to calibrate logistic fits to their populations terminate earlier, in 2030 and 2010 respectively. 
Since what is of principal interest here is labor supply and its corresponding economic production and energy use, what this in effect assumes is that the labor supply evolves monotonically even if the overall population eventually declines slightly. Population estimates are from Maddison [16] through 2009, and thereafter from UN estimates [17] rescaled to match Maddison's for 2009. Per capita GDP formulas are similarly calibrated, using time series data as described in Appendix G. For the Nigeria group, data on per capita GDP is not adequate to extrapolate an inflection time in the present millenium, so the inflection time for the GDP fit is set equal to the inflection time for the population fit. The fitting parameters for per capita GDP and the other parameters are listed in Tables 1-3. (The long-term limit per capita GDP figures listed as $B_{3}$ in Table 3 are in US\$1990, and must be multiplied by 1.73 to convert to US\$2012 if the U.S. consumer price index is used for this conversion.) Throughout Appendices B-E, functional fits are by least squares except where round numbers as listed in the tables included here are used to account for events with a priori known or assumed timing. The relevant numbers in Tables 1 and 2 for logistic function inflection are defined by times in dimensional units of years. Because the time-shifted unit logistic function of time $t_{y}$ appears frequently here, we adopt for it the shorthand notation

$$
\mathcal{L}_{X}=1 /\left[1+e^{-\left(t_{y}-X_{1}\right) / X_{2}}\right]
$$

Here the subscript $\mathrm{X}$ is replaced by A for population, B for GDP, etc. With this notation $t_{y}$ and $X_{1}$ are in Julian years and $X_{2}$ is in Julian calendar years, approximated as 365.25 days per year over the range of years of primary interest. In this notation we have the logistic function $a=1 /\left[1+e^{-\left(\nu\left(t-t_{1}\right)\right.}\right]=$ $1 /\left[1+e^{-\left(t_{y}-B_{1}\right) / B_{2}}\right]=\mathcal{L}_{B}$ where the values of $B_{1}=\bar{t} t_{1}$ and $B_{2}=\bar{t} / \nu$ are listed respectively in Tables 1 and 2. For cases for which logistic function parameters not listed in Tables 1 and 2, the notation $\mathcal{L}\left[X_{1}, X_{2}\right]=1 /\left[1+e^{-\left(t_{y}-X_{1}\right) / X_{2}}\right]$ is used.

Table 1. Inflection dates for logistic functions.

\begin{tabular}{cccccccccc}
\hline & China & India & Nigeria & Brazil & Ethiopia-Egypt & Indonesia & EU & USA & Japan \\
\hline$A_{1}$ & 1965.8 & 1999.0 & 2060.7 & 1986.0 & 2021.9 & 1986.7 & 1936.0 & 1993.2 & 1940.7 \\
$B_{1}$ & 2016.6 & 1999.7 & 2060.7 & 2083.0 & 1971.6 & 2041.4 & 1964.3 & 1971.4 & 1965.5 \\
$G_{1}$ & 1981.5 & 1996.1 & 1984.2 & 1994.7 & 2018 & 1984.5 & 1984.9 & 1981.9 & 1981.8 \\
$H_{1}$ & 2014.3 & 2011.5 & 2015 & 2008.0 & 2018 & 1998 & 2009.8 & 2012.6 & 2015.1 \\
$L_{1}$ & 2006 & 1990 & 2000 & 2004 & 2002 & 1988 & 1990 & 1960 & 1984 \\
\hline
\end{tabular}

Table 2. Timescales (in Years) for logistic functions.

\begin{tabular}{cccccccccc}
\hline & China & India & Nigeria & Brazil & Ethiopia-Egypt & Indonesia & EU & USA & Japan \\
\hline$A_{2}$ & 19.14 & 28.97 & 33.94 & 25.30 & 30.01 & 27.51 & 19.00 & 48.62 & 22.93 \\
$B_{2}$ & 13.25 & 11.28 & 110.09 & 83.01 & 29.04 & 36.64 & 26.70 & 29.91 & 11.22 \\
$G_{2}$ & 2.09 & 27.49 & 4.66 & 7.53 & 0.50 & 1.19 & 4.79 & 5.28 & 3.71 \\
$H_{2}$ & 0.41 & 0.89 & 3 & 2.10 & 3 & 0.01 & 2.45 & 0.22 & 0.67 \\
$L_{2}$ & 2 & 2 & 1 & 3 & 3 & 5 & 5 & 5 & 5 \\
\hline
\end{tabular}


For earlier data, from 1950 to the years $t_{y 1}$ noted above for calibration of later evolution of per capita GDP, simple empirical functions of the form $C_{3} /\left(1+c_{4} e^{-\left(t_{y}-C_{1}\right) / C_{2}}\right)$ were used. The functional form chosen allows for an early phase of growth that is logistic if $C_{1}>0$, approximately exponential if $C_{1} \approx 0$, or "super-exponential" (heading towards but never reaching explosive growth) if $C_{1}<0$. The values of $C_{2}$ and $C_{3}$ are listed in Table 3. The values for the Brazil group of $C_{24}=1.40 \times 10^{9}$ and $C_{34}=-5.39 \times 10^{-8}$ are indicative of a phase of growth that is nearly exactly exponential from 1950 to 1961.

Table 3. Additional region-dependent constants.

\begin{tabular}{cccccccccc}
\hline & China & India & Nigeria & Brazil & Ethiopia-Egypt & Indonesia & EU & USA & Japan \\
\hline$A_{0}$ & 0.39 & 0.22 & 0.05 & 0.02 & 0.04 & 0.05 & 0.23 & 0.01 & 0.03 \\
$A_{3}$ & 1.53 & 2.80 & 3.63 & 0.82 & 1.42 & 0.97 & 0.83 & 0.59 & 0.14 \\
$B_{0}$ & 0.23 & 0.14 & 0.02 & 0.01 & 0.02 & 0.03 & 0.23 & 0.01 & 0.02 \\
$B_{3}$ & 46.11 & 5.76 & 6.75 & 46.11 & 6.52 & 46.11 & 18.98 & 46.11 & 23.26 \\
$C_{1}$ & 2022.1 & 2036.1 & 1964.3 & 1985.1 & 1945.4 & 1953.9 & 1962.0 & 1940.4 & 1969.3 \\
$C_{2}$ & 30.44 & 184.06 & 1.71 & $C_{24}$ & 4.57 & 21.44 & 16.15 & -99.45 & 11.22 \\
$C_{3}$ & -3.99 & -0.30 & 1.02 & $C_{34}$ & 1.57 & 2.44 & 11.20 & 11.34 & 0.36 \\
$C_{4}$ & -1 & -1 & 1.02 & 1 & -1 & 1 & 1 & 1 & 1 \\
$D_{3}$ & 0.74 & 0.73 & 0.75 & 0.49 & 0.62 & 0.61 & 0.43 & 0.63 & 0.60 \\
$E_{3}$ & 0.10 & 0.02 & 0.003 & 0.79 & 0.003 & 0.09 & 1.13 & 1.86 & 0.01 \\
$F_{3}$ & 23.96 & 13.21 & 14.11 & 9.63 & 2.15 & 3.01 & 8.04 & 6.95 & 0.89 \\
$G_{3}$ & $0.85 \%$ & $0.89 \%$ & $1.02 \%$ & $1.23 \%$ & $0.47 \%$ & $2.59 \%$ & $9.04 \%$ & $7.74 \%$ & $1.23 \%$ \\
$H_{3}$ & $0.54 \%$ & $0.54 \%$ & $-0.05 \%$ & $-0.40 \%$ & $0.0004 \%$ & $0.94 \%$ & $-1.31 \%$ & $-2.06 \%$ & $5.61 \%$ \\
\hline
\end{tabular}

\section{Energy Consumption}

Expansion is taken only to lowest order in the shadow effect of future reduction in carbon intensity $\epsilon$, where $\epsilon$ is the initial value of $(1 / p) /(d p / d t)$ and $p$ is the carbon/energy use rate ratio divided by that for coal. (The symbol $p$ is used here as a reminder that $1 /(1+\mathrm{hp})$ reflects the amount of capital and labor needed for a given rate of energy consumption and is thus related to the price of energy.) With this approximation, we obtain the algebraic result $k=\ell=1$ where $k$ and $\ell$ are respectively proportional to the fraction of total capital and labor in the energy sector. Otherwise still $k=\ell$, but it is necessary also to solve a set of second order differential equations for $k$. The shadow effect is a measure of how expectation of future difficulties with using fossil carbon affect current prices. The results shown in Figures 4 and 5 suggest that the time scales for depletion of fossil fuels to escalate prices is long compared to the capitalization time $\bar{t} \approx 7.8$ years. It would be interesting to compare the results shown in this paper to data-calibrated integrations from terminal sustainable boundary conditions of the fourth order set of equations obtained without expansion in either $\delta$ or $\epsilon$, but this demanding exercise is beyond the scope of the present paper. With the approximation used here, the ratio of annual energy use rate to GDP is simply proportional to $1+h p$.

The solution to the above welfare maximization problem depends on how carbon intensity $p$ evolves with time. As a first approximation, we use historical time-series data to extrapolate $p$ as starting at 1 and 
declining exponentially towards a lower limiting value. That is, the starting points for the iteration are of the form $p=D_{3}+\left(1-D_{3}\right)\left(1-e^{-\left(t_{y}-D_{1}\right) / D_{2}}\right)$. Once the resulting total energy use rates are broken down into a different set of constituent sources for each country group, as described below, a new estimate for $p$ is obtained. The evolution of energy use rates is then re-computed. For the results shown here, a single iteration of this type is used. Normalized to that for coal, the carbon intensity of oil taken to be 0.75 and that for natural gas is taken to be 0.54 . Non-fossil electrical energy sources are approximated as having zero carbon intensity. (This approximation is initially sufficient for our purposes, and becomes more accurate as non-fossil energy sources are increasingly used for the industrial inputs to construction of non-fossil electrical energy facilities.) For biofuels we count as energy sources only the net solar energy content of the fuels. This is taken to be 0.6 times the biodiesel combustion energy. For fuel ethanol the net solar energy content is taken to be 0.23 times the combustion energy in temperate regions and 0.875 times the combustion energy in other regions. This is based on an observation that trade between regions producing fuel ethanol primarily from edible food products and from sugar cane tends to be a small fraction of total fuel ethanol use in each country group, and the production of ethanol from sugar cane requires a lower non-solar energy input. Based on historical trends only, each country group has been headed towards a limit carbon/energy ratio, normalized to that for coal, of the values for $D_{3}$ listed in Table 3. Tables 4 and 5 list starting years $Y_{1}$ and timescales $Y_{2}$ for functions of the form $e^{-\left(t_{y}-Y_{1}\right) / Y_{2}}$, including the values of $D_{1}$ and $D_{2}$.

Table 4. Starting dates for exponential functions.

\begin{tabular}{cccccccccc}
\hline & China & India & Nigeria & Brazil & Ethiopia-Egypt & Indonesia & EU & USA & Japan \\
\hline$D_{1}$ & 1935.4 & 1935.9 & 1937.8 & 1912.3 & 1927.6 & 1923.4 & 1945.4 & 1929.6 & 1919.9 \\
$E_{1}$ & 2002.3 & 2009.5 & 2005.7 & 2003.7 & 2007.0 & 2006.6 & 2003.6 & 2003.7 & 2008 \\
$F_{1}$ & 2014.8 & 2049.8 & 2067.9 & 1996.3 & 2018.0 & 2009.5 & 1967.8 & 1967.3 & 1952.8 \\
\hline
\end{tabular}

Table 5. Timescales (in Years) for exponential functions.

\begin{tabular}{cccccccccc}
\hline & China & India & Nigeria & Brazil & Ethiopia-Egypt & Indonesia & EU & USA & Japan \\
\hline$D_{2}$ & 117.15 & 24.35 & 31.17 & 44.27 & 24.37 & 52.52 & 53.96 & 22.96 & 40.01 \\
$E_{2}$ & 6.37 & 1.47 & 6.05 & 4.23 & 0.02 & 1.91 & 8.97 & 6.27 & 4 \\
$F_{2}$ & 5.51 & 21.43 & 21.64 & 11.86 & 17.08 & 17.50 & 11.34 & 13.08 & 10.82 \\
\hline
\end{tabular}

Once an iterated estimate for the evolution of carbon intensity $p$ of energy production is obtained, first approximations to the increases in energy use rates over 1820 levels are $R_{E}(1+h p) A_{3} \mathcal{L}_{A} B$. Here $R_{E}$ is a different constant for each country group as listed in Table $6, A_{3} \mathcal{L}_{A}$ are the population increments over 1820 levels, and $B$ denotes the per capita GDP functions described above. The smooth evolution of energy use rates that these functions describe has been interupted by various events such as China's "Great Leap," major economic reform, the partition of the Soviet Union, major recessions in the United States, and the 2011 tsunami in Japan. To account for such events, the formula $R_{E}(1+h p) A_{3} \mathcal{L}_{A} B$ is 
multiplied by a different function $f_{\text {fix }}$ for each country group to account for some anomalies that interrupt the overall evolutionary trends. For the China group, the fit to the ratio of annual energy use (in EJ) to GDP (in T\$US1990PPP) is multiplied by $f_{\text {fix }}=f_{11} f_{12} f_{13}$ where $f_{11}=1.267(1-0.414 \mathcal{L}[1993.1,3.84]$ ), $f_{12}=0.414-0.586 \mathcal{L}[1965.2,4.13]$, and $f_{13}=(1+8.402(1-\mathcal{L}[1959.3,0.92])(1-\mathcal{L}[1959.3,0.92])$. The factor $f_{11}$ accounts changes after the launch of economic reform. The other two factors account for the "Great Leap" period's energy use inefficiency.

For the India group, $\left.f_{\text {fix }}=0.348-0.652 \mathcal{L}[1960.1,5.52]\right)$. For the Nigeria, Brazil and Indonesia groups, $f_{\text {fix }}=1$. For the EU group, the presumably unique events associated with the partition of the Soviet Union give $0.978+0.315 \mathcal{L}[1965.3,2.98]-0.455 \mathcal{L}[1992.5,2.72]$ for $f_{\text {fix }}$. For the USA group, $f_{\text {fix }}=(1.707-0.706 \mathcal{L}[1981.8,3.40])(1-0.370 \mathcal{L}[2008.2,2.92])$ accounts for the impact of two major recessions. For Japan there is a transient energy use rate above the background trend preceding the 1973 oil price increase and a presumably transient decrease associated with recent economic upsets including the 2011 tsunami. To account for this events, the formula for $f_{\text {fix }}$ for Japan is set to $f_{91} f_{92} f_{93}$ where $\left.f_{91}=1,775-0.177 \mathcal{L}[1961.3,4.19]\right), f_{92}=1+1.962(1+(1-\mathcal{L}[1972.2,2,56]) \mathcal{L}[1972.2,2,56])$, and $f_{93}=1-0.1 \mathcal{L}[2009,1]+0.1 \mathcal{L}[2014,1]$. The long-term limits for the functions $f_{\text {fix }}$ are equal to 1 except for 0.743 for the China group, 0.837 for the EU group, and 0.630 for the USA group. These numbers give some idea of the minimum uncertainty in the long-term extrapolations, since different results differing by the magnitudes for which some of the long-term $f_{\text {fix }}$ differ from 1 would be expect to result from using different functional forms $f_{\text {fix }}$ (e.g., allowing for the possibility of future major recessions in the USA group).

\section{Energy Sources}

The division of total energy use rates into different energy sources starts with conventional biofuels. The sum of annual conventional (biodiesel and non-cellulosic ethanol) biofuels consumption in each region is approximated as nil until a time $E_{1}$ and of the form $f_{\text {bio }}=E_{3}\left(1-e^{-\left(t_{y}-E_{1}\right) / E_{2}}\right)$ thereafter. The same type of formula, $f_{\text {water }}=F_{3} \operatorname{Max}\left[0,1-e^{-\left(t_{y}-F_{1}\right) / F_{2}}\right]$, is used for water-driven electrical energy, with the long-term limit from estimates of hydropower potential capacity [18] times the ratio of U.S. actual hydropower to potential capacity. (Tidal and geothermal electric energy capacities are assumed to be so small in comparison to uncertainties in hydroelectric capacity that they do not need to be accounted for separately when prescribing the long-term limit rates of consumption of water-driven electricity.) These contributions to energy use are assumed to be limited by suitable cropland and watershed availability and thus are not proportional to total energy use.

The fraction of total thermal equivalent energy from nuclear reactors in each region is approximated as evolving as $f_{\text {on }} G_{3} \mathcal{L}_{G}+f_{\text {off }} H_{3} \mathcal{L}_{H}$. Except for India and Japan, $f_{\text {on }}=1$. For India, $f_{\text {on }}=\mathcal{L}[2009,0.5]$, and for Japan $f_{\text {on }}=\mathcal{L}[2012.5,0.5]$. Except for Japan, $f_{\text {off }}=1$. For Japan, $f_{\text {off }}=1-\mathcal{L}[2011,0.5]$. For the India group, including the factor $f_{\text {on }}$ helps fit the nearly linear build up of nuclear energy use from 1990 to 2010. For Japan, the parameters in $f_{\text {on }}$ and $f_{\text {off }}$ are chosen to model the expected effects of the year 2011 tsunami.

The fraction of total thermal equivalent energy consumption rate from new renewables (wind- and solar-electric energy) is approximated for each region as nil for $t_{y}<I_{1}$, and as $I_{2} /\left[1+I_{5} e^{\left(-I_{3}+I_{2} E_{\text {total }}\right) / I_{4}}\right]$ for $t_{y}>I_{1}$. Here $E_{\text {total }}$ is cumulative energy use in EJ each region after year $I_{1}$. The values of the 
constants in this formula are given in Table 6, with the units of the value for $I_{5}$ being EJ. This formula results from assuming that the fraction of the total energy market in each region that is acquired by new renewables is proportional to an exponentially saturating function $1-e^{-W / I_{5}}$ of cumulative production $W$ from new renewables (which are so far mostly wind energy). Due to the limited experience of the Nigeria group with new renewable electrical energy sources, the fraction of total energy from those sources is set to its year 2012 value of 0.000137 instead of using the formula corresponding to the parameters in Table 6. This limitation for the Nigeria group is a reflection of limited infrastructure for managing grid-connected wind and solar electric energy production. This is in a context where the substitution of wind and solar energy sources for wood and other energy sources not included in our database is assumed to be part of the "preindustrial" part of the economy that is not analyzed here because such substitutions are approximated as not materially affecting global fossil carbon burning.

The total cumulative fossil energy use $E_{\text {fossil }}$ is calculated for each region as total thermal equivalent energy use less the thermal equivalent of the non-fossil energy sources estimated as described in the preceeding three paragraphs. The cumulative use $E_{\mathrm{ff}}$ of fluid fossil fuels solves the equation $d E_{\mathrm{ff}} / d t_{y}=J_{1}\left(1-e^{-E_{\mathrm{ff}} / J_{2}}\right) d E_{\mathrm{fossil}} / d t$, subject to the boundary condition that $E_{\mathrm{ff}}$ is equal to the cumulative use $J_{3}$ of fluid fossil fuels through 2012 as estimated from the database. The values of $J_{1}, J_{2}$ and $J_{3}$ are listed in listed in Table 6, with $J_{2}$ and $J_{3}$ in EJ. It is convenient to integrate this equation numerically. The same applies to the natural gas fraction of fluid fossil fuels, discussed in the next paragraph.

As a first approximation, the cumulative consumption $E_{\text {gas }}$ of natural gas solves the equation $d E_{\text {gas }} / d t_{y}=K_{1} E_{\mathrm{ff}}\left(1-e^{-E_{\text {gas }} / K_{2}}\right)$, subject to the boundary condition that $E_{\text {gas }}$ is equal to the cumulative use $K_{3}$ of fluid fossil fuels through 2012 as estimated from the database. The results of this calculation for $E_{\text {gas }} / d t$ are multiplied for each region by an empirical correction factor of the form $L_{4}+L_{3} \mathcal{L}_{L}$. The values of the constants in these formulas are listed in Table 6. To account for the presumably partly temporary shut down of Japanese nuclear reactors following the 2011 tsunami, for Japan an additional multiplicative factor of $1+0.352\left(1 /\left[1+e^{-(t-2011)}\right]-0.487\left[1+e^{-(t-2011)}\right]\right)$ was included. Here 0.487 is an estimate of the fraction of Japan's nuclear capacity that will come back on line if all of its pressurized water reactors and advanced boiling water reactors restart, but the remaining reactors do not (based on reported reactor capacities [19]). For 2010 through 2012, the Nigeria group's natural gas consumption was much lower than in the eleven preceding years. This was because exports of liquefied natural gas continued despite the shut down of a large Nigerian natural gas production facility [20]. Unlike the expected extensive shutdown of about half of Japan's nuclear reactor fleet, the disruption of natural gas consumption in Nigeria is assumed here to be temporary and thus not accounted for with another special multiplicative factor. Disruption of Libyan natural gas consumption in 2011 and 2012 and reductions in Iranian natural gas consumption from 2010-2012 were also assumed to be temporary and thus not accounted for with a special multiplicative factor. 
Table 6. Region-dependent constants for experiential learning.

\begin{tabular}{cccccccccc}
\hline & China & India & Nigeria & Brazil & Ethiopia-Egypt & Indonesia & EU & USA & Japan \\
\hline$I_{1}$ & 1990 & 1986 & 2002 & 1990 & 1986 & 1990 & 1978 & 1999 & 1995 \\
$I_{2}$ & 0.064 & 0.070 & 0.030 & 0.067 & 0.057 & 0.056 & 0.061 & 0.068 & 0.055 \\
$I_{3}$ & 2.651 & 1.498 & 0.026 & 0.234 & 0.231 & 0.517 & 11.793 & 5.947 & 0.518 \\
$I_{4}$ & 26.73 & 8.18 & 3.90 & 7.53 & 8.32 & 9.94 & 37.27 & 26.18 & 6.63 \\
$I_{5}$ & 10.59 & 5.98 & 149.08 & 32.64 & 36.54 & 19.72 & 3.68 & 4.92 & 13.31 \\
$J_{1}$ & 0.211 & 0.582 & 0.504 & 0.939 & 0.936 & 0.736 & 0.706 & 0.782 & 0.785 \\
$J_{2}$ & 5.90 & 9.53 & 4.62 & 5.71 & 1.90 & 10.29 & 312.90 & 200.83 & 13.26 \\
$J_{3}$ & 503.7 & 517.5 & 190.9 & 930.8 & 936.8 & 689.8 & 3944.0 & 4185.6 & 559.6 \\
$K_{1}$ & 0.201 & 0.464 & 0.331 & 0.338 & 0.504 & 0.329 & 0.531 & 0.428 & 0.362 \\
$K_{2}$ & 28.1 & 33.3 & 17.0 & 35.6 & 8.8 & 31.3 & 330.6 & 0.3 & 49.7 \\
$K_{3}$ & 62.1 & 214.7 & 45.8 & 306.5 & 444.9 & 185.5 & 1552.8 & 1734.5 & 91.7 \\
$L_{3}$ & 0.55 & 0.35 & 1.2 & 0 & 0.15 & 0.66 & 0.42 & 0.11 & 0.6 \\
$L_{4}$ & 0.43 & 0.60 & 0.2 & 1.03 & 0.98 & 0.38 & 0.60 & 0.89 & 0.01 \\
$R_{E}$ & 6.64 & 4.51 & 6.85 & 5.18 & 8.66 & 4.62 & 7.48 & 7.16 & 4.18 \\
\hline
\end{tabular}

For the case where future nuclear energy use is dramatically increased rather than relying on stratospheric sulfur injection later supplemented with extensive carbon sequestration, the nuclear energy use fraction described above is multiplied by a factor $\left[1+\left(M_{3}-1\right) \mathcal{L}_{M}\right] f_{\text {late }}$. Here $f_{\text {late }}=1$, except that $f_{\text {late }}$ is set equal to $0.075 \mathcal{L}[150,20]$ and $0.050 \mathcal{L}[150,20]$ respectively for the slowly developing Nigeria and Brazil groups. The other constants used in this formula are given in Table 7.

Table 7. High nuclear case multiplier constants.

\begin{tabular}{cccccccccc}
\hline & China & India & Nigeria & Brazil & Ethiopia-Egypt & Indonesia & EU & USA & Japan \\
\hline$M_{1}$ & 2035.5 & 2052 & 2067 & 2067 & 2052 & 2062 & 2050 & 2042 & 2052 \\
$M_{2}$ & 5 & 10 & 10 & 10 & 10 & 10 & 6 & 6 & 10 \\
$M_{3}$ & 57.5 & 58.7 & 99.0 & 77.0 & 165.0 & 27.1 & 10.75 & 11.7 & 12.7 \\
\hline
\end{tabular}

\section{E. Global Heat and Carbon Balances}

Milligan [21] describes an adaptation of a global heat balance model due to Fraedrich [22] to solve for a temperature anomaly $\tau=T-T_{0}$, where $T_{0}=286.48^{\circ} \mathrm{K}$ and $T$ is global average temperature in ${ }^{\circ} \mathrm{K}$ :

$$
c_{\text {heat }} d \tau / d t_{s}=\mu\left(I_{0} / 4\right)\left(1-a_{2}+b_{2} T^{2}\right)-\sigma T^{4}\left(e_{4}-\kappa T^{2}\right)
$$

Here $t_{s}$ is time in seconds from the beginning of Julian year $1000, I_{0}=1,366 \mathrm{~W} / \mathrm{m}^{2}$ is the timeaveraged solar irradiance, and $\sigma=5.6704 \times 10^{-8} \mathrm{~W} /\left(\mathrm{m}^{2}{ }^{\circ} \mathrm{K}^{4}\right)$ is the Stefan-Boltzman constant. The temperature dependence of the albedo is determined by $a_{2}=1.160$ and $b_{2}=1.045 \times 10^{-5} /\left({ }^{\circ} \mathrm{K}\right)^{2}$, 
which give an albedo of 0.30 when $T=T_{0}$. The temperature-dependent part of the effective emissivity, $\left(e_{4}-\kappa T^{2}\right)$, is determined by the value of $\kappa=3 \times 10^{-6} /\left({ }^{\circ} \mathrm{K}\right)^{2}$. The effective emissivity is also influenced by the atmospheric $\mathrm{CO}_{2}$ concentration through the relationship $e_{4}=0.870846-e_{1} \mathrm{Ln}\left(\left[\mathrm{CO}_{2}\right] /\left[\mathrm{CO}_{2}\right]_{0}\right)$. Here $\left[\mathrm{CO}_{2}\right]_{0}=280 \mathrm{ppmv}$ and $\left[\mathrm{CO}_{2}\right]$ is the atmospheric $\mathrm{CO}_{2}$ concentration in ppmv. The constant $e_{1}=0.00688$ determines $\mathrm{CO}_{2}$ forcing of global average temperature in the context of this model and was adjusted to give a equilibrium carbon forcing increment in $\tau$ of $3.0^{\circ} \mathrm{K}$ for a doubling of atmospheric $\mathrm{CO}_{2}$ concentration from $280 \mathrm{ppmv}$ to $560 \mathrm{ppmv}$ [23]. The ocean mixed layer thermal inertia constant is $c_{\text {heat }}=f_{\text {ocean }} \rho_{\text {sea }} C_{p} d_{\text {mixed }}$, where $f_{\text {ocean }}=3.6 / 5.1$ is the fraction of the earth's surface area covered by ocean, the seawater density is $\rho_{\text {sea }}=1,027 \mathrm{~kg} / \mathrm{m}^{3}$, and $C_{p}=3,985 \mathrm{~J} /\left(\mathrm{kg}{ }^{\circ} \mathrm{K}\right)$ is the heat capacity of sea water. An ocean mixed layer depth of $335 \mathrm{~m}$ was chosen to fit global average temperature data from 1850-2013. This was done by choosing the integer value in meters for $d_{\text {mixed }}$ that minimized variance between the computed and observed results, while also adjusting a constant offset between data and computation to minimize variance.

Oscillations in solar irradiance are given by $\mu=\Sigma_{j=1}^{4} \rho_{j} \cos \left[\omega_{j}\left(t_{y}-u_{y}\right)\right]$, where $t_{y}$ is time in Julian years. These oscillations are all in phase at maximum when $u_{y}=1,994.3$ Julian years. The four periods are $2 \pi / \omega_{j}=\{11,22,88,600\}$ years, and the respective amplitudes $\rho_{j}$ are $\{0.25,0.05,0.2,0.4\} / 1,000$. These amplitudes determine the size of the preindustrial variations in $\tau$ shown in Figure 2. These amplitudes are smaller than early estimates by Lean et al. [24] used by Milligan [21], and more in line with more recent estimates by Steinhilber et al. [25].

The annual rate of change of the sum $c_{a}+c_{w}+c_{v}+c_{s}$ of carbon respectively in the atmosphere, surface ocean water, vegetation, and soil is set equal to the difference $R_{f}-R_{m}$ between the global fossil carbon emission rate, $R_{f}$, and the rate $R_{m}$ of removal of carbon from the surface mixed ocean layer to the deep ocean due to the difference between $c_{w}$ and its preindustrial average value $c_{w 0}$. That rate is $R_{m}=\left(c_{w}-c_{w 0}\right) / t_{m}$ with $t_{m}=173$ years [23]. Equilibration between the atmosphere and surface ocean layer is assumed to occur rapidly enough to be approximated algebraically as in equilibrium [26]. Two of the remaining three differential equations are $d c_{s} / d t_{y}=R_{\ell}-R_{s}$ for soil and $d c_{v} / d t_{y}=R_{p}-R_{v}-R_{\ell}$ for vegetation. Defined below are the rates $R_{\ell}, R_{s}, R_{p}$ and $R_{v}$ of carbon transfer respectively from litter fall, soil respiration, photosynthesis, and respiration by vegetation. (We have not attempted to model the effect of land use changes on carbon in vegetation, as this difficult to extrapolate.) The relationship between the molar concentration $c_{w} / v_{m}$ in the surface ocean mixing layer and the volume fraction $c_{a} / v_{a}$ in the atmosphere depends on the ratio $z_{1}$ of the bicarbonate dissociation constant $k_{1}$ to the hydrogen ion activity $a_{H}$ as

$$
c_{w} / v_{w}=k_{s}\left(1+z_{1}+\left(k_{2} / k_{1}\right) z_{1}^{2}\right) c_{a} / v_{a}
$$

Here $v_{m}$ is 4.348 times the surface ocean mixing layer depth in meters, and $v_{a}=2,130$ ppmv per Ttonne of elemental carbon.

The temperature dependence of the solubility constant, bicarbonate dissociation constant, and carbonate dissociation constant, $k_{2}=a_{H}\left[\mathrm{CO}_{3}^{=}\right] /\left[\mathrm{HCO}_{3}^{-}\right]$, are respectively

$$
\begin{aligned}
& k_{s}=\left(770-29.5 T_{c}+0.685 T_{c}^{2}-0.0075 T_{c}^{3}\right) 10^{0.0074 T_{c}-0.0806} \\
& k_{1}=10^{-\left(6.34-0.01 S_{\mathrm{ppt}} / 1.80655-\left(0.008-0.00008 T_{c}\right)\right)} \\
& k_{2}=10^{-\left(9.78-0.02 S_{\mathrm{ppt}} / 1.80655-0.012 T_{c}\right)}
\end{aligned}
$$


where $T_{c}$ is the temperature on the Celsius scale. The salinity is approximated as $S_{\mathrm{ppt}}=35$. Accounting for borate buffering from a total molar boron concentration of $B_{m}=0.004106$ and dissociation constant $k_{b}=a_{H}\left[\mathrm{~B}(\mathrm{OH})_{4}^{-}\right] /\left[\mathrm{B}(\mathrm{OH})_{3}\right]=10^{-p k_{b}}$ with $p k_{b}=9.26-0.01 S_{\mathrm{ppt}} / 1.80655-0.01 T_{c}$, the ratio $z_{1}$ satisfies the cubic equation $0=z_{1}^{3}+a_{2} z_{1}^{2}+a_{1} z_{1}+a_{0}$.

Since derivatives of $z_{1}$ with respect to $T_{c}$ need to be chain-rule coupled to time derivatives of $T_{c}$, it is convenient to pick out the physically appropriate root of the cubic equation for $z_{1}$. This root is given by $z_{1}=s_{z}+t_{z}-a_{2} / 3$ where $t_{z}=\left(r_{z}+\sqrt{d}_{z}\right)^{1 / 3}$ and $s_{z}=\left(r_{z}-\sqrt{d}_{z}\right)^{1 / 3}$ with $d_{z}=q_{z}^{3}+r_{z}^{2}$, $r_{z}=\left(9 a_{2} a_{1}-27 a_{0}-2 a_{2}^{3}\right) / 54$, and $q_{z}=\left(3 a_{1}-a_{2}^{2}\right) / 9$. The expressions for the coefficients in the cubic equation are

$$
\begin{aligned}
& a_{2}=\frac{\left(2 k_{2}+k_{b}\right) k_{1}}{2 k_{2} k_{b}} \\
& a_{1}=\frac{k_{1}}{2 k_{2}}\left(\frac{k_{1}}{k_{b}}-\frac{A_{c b}-B_{m}}{k_{s} c_{a} / v_{a}}\right) \\
& a_{0}=-\frac{k_{1}^{2} A_{c b}}{2 k_{2} k_{b} k_{s} c_{a} / v_{a}}
\end{aligned}
$$

where $A_{c b}=0.00223$.

With the above algebraic relations in hand for the dependence $c_{w}\left(c_{a}, T_{c}\right)$ of the ocean mixed layer carbon content on atmospheric carbon content and temperature, one can write the rate of change of the sum of atmospheric and mixed ocean layer content as $d c_{a} / d t_{y}$ plus $d c_{w} / d t_{y}$ where $d c_{w} / d t_{y}=\left(\partial c_{w} / \partial c_{a}\right) d c_{a} / d t_{y}+\left(\partial c_{w} / \partial T_{c}\right) d T_{c} / d t_{y}$. With the above equations $d c_{s} / d t_{y}=R_{\ell}-R_{s}$ for soil and $d c_{v} / d t_{y}=R_{p}-R_{v}-R_{\ell}$ for vegetation, we can then include

$$
\left(d c_{a} / d t_{y}\right)\left(1+\left(\partial c_{w} / \partial c_{a}\right)\right)=R_{f}+R_{s}+R_{v}-R_{p}-R_{m}-\left(\partial c_{w} / \partial T_{c}\right) d T_{c} / d t_{y}
$$

The fractional carbon respiration rate $R_{s} / c_{s}$, and fractional vegetation carbon respiration rate $R_{v} / c_{v}$ increase respective by factors of $\sqrt{2.40}$ and $\sqrt{2.15}$ for a $5{ }^{\circ} \mathrm{C}$ of temperature increase photosynthesis are respectively, and they have carbon turnover timescales respectively of 30 and 11 years. The litter fall carbon rate is simply $R_{\ell}=c_{v} / 11$. The rate of carbon uptake into vegetation depends both on temperature and atmospheric carbon content. Inclusion of the constant $c_{v s 0}$ in the following expression for $R_{p}$ is a consequence of not accounting for any change in the areal extent of vegetation cover.

$$
\begin{aligned}
& R_{s}=2.40^{T_{c} / 10} c_{s} / 30 \\
& R_{v}=2.15^{T_{c} / 10} c_{v} / 11 \\
& R_{p}=\left(1.5^{T_{c} / 10} / 3.443\right) c_{v s 0}\left(c_{a}-0.0618\right) /\left(0.2577+c_{a}\right)
\end{aligned}
$$

The coupled global carbon and heat balance equations are integrated forward from Julian year 1000, with starting conditions $-0.062429{ }^{\circ} \mathrm{C}$ for $\tau$, for 1.5 Ttonne for $c_{a}, 0.55$ Ttonne for $c_{v}$, and 0.55 Ttonne for $c_{s}$.

\section{F. Effect of Fuel Resource Depletion}

Logarithmically averaged over commodity price variations, the evolution of uranium prices with cumulative global use in \$US2012/kgU is initially

$$
88.58\left(U_{\text {tot }} / 2.17\right)^{2 / 9}
$$


where $U_{\text {tot }}$ is cumulative global elemental uranium use in millions of metric tons. Uranium extraction from natural resources is assumed to proceed by successively extracting both more readily accessible lower grade ores and less accessible higher grade ores, up to a threshold where open pit and underground uranium mine depths reach present limits of open pit copper and underground gold mine depths, respectively. Thereafter, i.e., when the price estimated from the following expression is larger than $88.58\left(U_{\text {tot }} / 2.17\right)^{2 / 9}$, the uranium price evolves as

$$
154.23\left(1+\sqrt{1+\left(2\left(U_{\text {tot }} / 26.31\right)-(35 / 4)\right) /(315 / 8)}\right.
$$

The wellhead cost of production of natural gas in $\$$ US2012/GJ is taken to evolve as $0.5694 U_{\text {gas }}^{0.7355}$, where $U_{\text {gas }}$ is cumulative global natural gas use in $\mathrm{ZJ}=10^{21} \mathrm{~J}$. The wellhead or minehead cost of production of oil in $\$$ US2012/barrel is taken to evolve as $3.4841 U_{\text {oil }}^{0.7}$, where $U_{\text {oil }}$ is cumulative global oil use in ZJ. The minehead cost of coal production in \$US2012/barrel is assumed to evolve as $0.462+0.016 U_{\text {coal }}$, where $U_{\text {coal }}$ is cumulative coal consumption in ZJ. For the lower curve case shown in Figure 1, the global average minehead cost of coal in 2100 is 1.5 \$US2012/EJ. Comparing this to the result for natural gas shown in Figure 4, it appears that the extent of burning coal without carbon sequestration will long be limited by tolerable atmospheric $\mathrm{CO}_{2}$ concentrations rather than be depletion of coal resources.

\section{G. Databases}

The data for GDP for the years 1820-2008 are from Maddison [16]. GDP estimates are in purchasing power parity in year 1990 U.S. dollars. For later years, International Monetary Fund [27] estimates and projections through 2018 were multiplied by a constant for each country to make those estimates consistent with the last year available in Maddison's database. For groups of countries where Maddison gave only aggregate estimates of population and GDP, these were disaggregated in proportion to UN estimates for each country. Since the present paper re-aggregates countries into larger groups, the method of disaggregation of Maddison's estimates has negligible effect on the results presented here. Allowing for a period of relaxation for areas involved in World War II, GDP data used started in 1961. Exceptions to the 1961 date are 2001 for the China group and 2003 for the India group, since the effects of earlier economic reforms showed up as a pronounced change in the rate of growth of per capita GDP in those years. For the Indonesia group the start year for GDP data use was 1967, before which per capita GDP growth rates were anomalously low.

The year 1820 value for population and GDP for each country group is subtracted from the data. The result for population is used to calibrate three parameters in a logistic fit. These are the initial exponentiation growth time, the time to half maximum, and the long-term limit value. The fit is accomplished by minimizing the variance of the difference between the logarithm of the data and the logarithm of the fitting function. The same procedure was used to fit data on the ratio of the GDP increment over 1820 values to the population increment over 1820 values.

The database for energy use rates has annual estimates from 1820-2012 for eleven parameters for each UN reporting unit (mostly but not all sovereign countries), except that Sudan and South Sudan are included together. These data are combined into the seven different energy types as described above. (For current countries previously part of larger reporting units, the earlier data is divided in 
proportion to split at the time of division, but for the results in the present paper all of these cases are re-aggregated into larger country groups.) Country-specific data from 1950-2010 are from the United Nations Energy Database [28]. For years after 2010, U.S. Energy Information Agency estimates [29] were used where they were available and British Petroleum estimates [30] where used where not, both scaled with a multiplicative factor to match the year 2010 UN estimates. For countries missing from the British Petroleum database, their portions of the BP regional sums not accounted for by individual countries in those sums were allocated in proportion to the most recent data available from other sources. Cumulative energy consumption rates from before 1950 were summed annual estimates based on Mitchell's Historical Energy Statistics [31], the UK statistical summaries of the mineral industry [32] and British [33] and U.S. [34] trade tables for exports of coal and oil by destination. The cumulative energy consumption rates before 1950 and the annual energy use rates from 1950-2012 for the above-mentioned seven energy types and the nine country groups are included in a table of supplementary material accompanying this paper.

\section{Acknowledgments}

This work was supported in part through U.S. National Science Foundation award 1243400-OISE and through the Cluster of Excelence "CliSAP" (EXC177), University of Hamburg, funded through the German Science Foundation (DFG).

\section{Conflicts of Interest}

The authors declare no conflict of interest.

\section{References}

1. Vaughan, N.; Lenton, T. A review of climate geoengineering proposals. Clim. Chang. 2011, 109, 745-790.

2. Satish, U.; Mendell, M.; Shekar, K.; Hotchi, T.; Sullivan, D.; Streufert, S.; Fisk, W. Is $\mathrm{CO}_{2}$ and indoor pollutant: Direct effects of low-to-moderate $\mathrm{CO}_{2}$ concentrations on human decision-making performance. Environ. Health Perspect. 2012, 120, 1671-1677.

3. Crutzen, P. Albedo enhancement by stratospheric sulfur injections: A contribution to resolve a policy dilemma? Clim. Chang. 2006, 77, 211-219.

4. Singer, C.; von Brevern, H. Uranium price vs. cumulative use. Nuclear Technol. 2011, 176, 227-237.

5. U.S. Bureau of Labor Statistics. Consumer Price Index: All Urban Consumers. 2013. Available online: ftp://ftp.bls.gov/pub/special.requests/cpi/cpiai.txt (accessed on 3 October 2013).

6. Levitan, D. Nuclear Fuel from the Sea, IEEE Spectrum. Available online: http://spectrum.ieee.org/energy/nuclear/nuclear-fuel-from-the-sea (accessed on 3 October 2013).

7. Rogner, H.-H. An assessment of world hydrocarbon resources. Ann. Rev. Energy Environ. 1997, 22, 217-262.

8. Anonymous. Can China Clean up Fast Enough? Climate Change. The Economist, 10 August 2013. 
9. Mendelsohn, R.; Morrison, W.; Schlesinger. M.E.; Androva, N.G. Country specific market impacts of climate change. Clim. Chang. 2000, 45, 553-569.

10. Bosello, F.; Roson, R. Estimating a Climate Change Damage Function Through General Equilibrium Modeling; Department of Economics, Ca' Foscari University of Venice: Venice, Italy, 2007.

11. Nordhaus, W.; Boyer, J. Roll the Dice again: Economic Models of Global Warming; MIT Press: Cambridge, MA, USA, 1999.

12. van Vuureen, D.; Edmonds, J.; Kainuma, M.; Riahi, K.; Thomson, A.; Hibbard, K.; Hurtt, G.; Kram, T.; Krey, V.; Lamarque, J-F.; Masui, T.; Meinshausen, M.; Nakicenovic, N.; Smith, S.; Rose, S.; The representative concentration pathways: an overview, Climatic Change 2011, 109, 5-31.

13. Emissions Scenarios Summary for Policymakers; Intergovernmental Panel on Climate Change: Geneva, Switzerland, 2000.

14. Singer, C.; Rethinaraj, T.; Addy, S.; Durham, D.; Isik, M.; Khanna, M.; Keuhl, B.; Luo, J.; Quimio, W.; Kothavari, R.; et al. Probability distributions for carbon emissions and atmospheric response. Clim. Chang. 2008, 88, 309-342.

15. Peters, J. Private Communication; Hamburg University: Hamburg, Germany, 2010.

16. Maddison, A. Historical Statistics of the World Economy: 1-2008 AD. Available online: http://www.ggdc.net/maddison/oriindex.htm (accessed on 3 October 2013).

17. United Nations Department of Economic and Social Affairs, Population Division. World Population Prospects: The 2010 Revision-Special Aggregates; United Nations Department of Economic and Social Affairs, Population Division: New York, NY, USA, 2011.

18. World Energy Council. 2010 Survey of Energy Resources; World Energy Council: London, UK, 2010.

19. CEA. ELECNUC: Les centrales nuclêaires dans le monde; CEA: Gif sur Yvette, France, 2012.

20. U.S. Energy Information Administration, Nigeria. Available online: http://www.eia.gov/countries/ analysisbriefs /Nigeria/nigeria.pdf (accessed on 3 October 2013).

21. Milligan, T. Development of an Econo-Energy Model and an Introduction to a Carbon and Climate Model for Use in Nuclear Energy Analysis. Masters Thesis, University of Illinois at UrbanaChampaign, Champaign, IL, USA, 2012. Available online: https://www.ideals.illinois.edu/handle/ 2142/31168 (accessed on 3 October 2013).

22. Fraedrich, K. Catastrophes and resilience of a zero-dimensional climate system with ice-albedo and greenhouse feedback. Q. J. R. Meteorol. Soc. 1979, 105, 147-167.

23. IPCC Working Group I. Climate Change 2001: The Physical Science Basis; Cambridge University Press: New York, NY, USA, 2007.

24. Lean, J.; Beer, J.; Bradley, R. Reconstruction of solar irradiance since 1610: Implications for climate change. Geophys. Res. Lett. 1995, 22, 3195-3198.

25. Steinhilber, F.; Beer, H.; Frölich, C. Solar irradiance during the Holocene. Geophys. Res. Lett. 2009, doi:10.1029/2009GL040142.

26. Eliseev, A.V.; Mokhov, I.I. Carbon cycle-climate feedback sensitivity to parameter changes of a zero-dimensional terrestrial carbon cycle scheme in a climate model of intermediate complexity. Theor. Appl. Climatol. 2007, 89, 9-24. 
27. International Monetary Fund Data and Statistics, 2013. Available online: http://www.imf.org/ external/data.htm (accessed on 3 October 2013).

28. United Nations Statisics Division. Energy Statistics Database, 1950-2008; United Nations: New York, NY, USA, March 2011.

29. U.S. Energy Information Administration. International Energy Statistics, 2013. Available online: http://www.eia.gov.ipdproject/ieindex3.cfm (accessed on 25 July 2013).

30. British Petroleum. Statistical Review of World Energy. Available online: http://www.bp.com/en/global/corporate/about-bp/statistical-review-of-world-energy-2013.html (accessed on 3 October 2013).

31. Mitchell, B. International Historical Statistics; Palgrave: New York, NY, USA, 2003.

32. Statistical Summary of the Mineral Industry (And Earlier Editions Starting with 1922); H.M. Stationery Office: London, UK, 1950.

33. Annual Statement of Trade of the United Kingdom (And Earlier Editions Starting with 1886); H.M. Stationery Office: London, UK, 1950.

34. Foreign Commerce and Navigation of the United States (And Earlier Editions Starting with 1867); U.S. Government Printing Office: Washington, DC, USA, 1947.

(c) 2014 by the authors; licensee MDPI, Basel, Switzerland. This article is an open access article distributed under the terms and conditions of the Creative Commons Attribution license (http://creativecommons.org/licenses/by/3.0/). 